\title{
ADAPTATION OF THE COURSE IN PHYSICS TO THE NEEDS OF GIRLS. ${ }^{1}$
}

\author{
By W. G. Whitman, \\ State Normal School, Salem, Mass.
}

Does not our experience show the futility of adapting all pupils to our one course in physics? Is it not more reasonable to look for better results if we adapt the physics we teach to our pupils? The idea that a pupil who has no aptitude and no liking for a particuiar subject, and who has no special need of it, should be compelled to take that subject to remedy his deficiency, is losing ground.

Broad changes in our educational policy are under way. We are committed to the idea of specialization; to adapting the subjects taught to the pupils' serious desire. In our schools there are different courses of study. In one city there may exist schools where different types of work are given: for example we have manual training, technical, trade, business, art and Latin schools. These schools recognize the different needs of different groups of pupils. Each school emphasizes one kind of training without eliminating all the others. They treat the subjects in a way to have a bearing upon the future occupation of the individual student. This separation of pupils into groups for special kinds of work is evidence of our belief in giving the pupil the kind of work which is thought best suited to his needs. It is not revolutionary then to apply the same principle to physics teaching. Within reasonable limits separate the pupils and select those portions of the subject for each group which can best be used by them.

As far as the studying of physics for its cultural value is concerned, it might be treated in much the same way for both boys and girls. Both would need the same general treatment for the broad understanding of natural forces without which a person would seem tunduly ignorant. But when we consider those parts of physics which are to be of special interest and profit to the pupil, there the work divides.

The majority of the girls will eventually find their way to take charge of the home. Our modern home is complex with its numerous scientific appliances. The girl cannot begin too early to prepare for her responsibilities. Among her problems will be,

\footnotetext{
${ }^{2}$ Abstract of paper given at meeting of New York State Science Teachers' Association at syracuse, December, 1909 .
} 
how to manage the household economically without sacrificing health. Involved in this problem are many questions of physics. The study of properly selected portions of physics will give her much valuable information and will guide her in proper methods of investigation. We must frame our course for the greater number of girls who present themselves. In a course for girls then we should give a broad treatment touching the whole field, though in some parts rather lightly; we must emphasize those portions which have direct bearing or application in the household.

The majority of the boys will go into business or mercantile work. They will at some time give all their time to acquiring proficiency in their chosen field, but in the high school they will be giving only partial time to the special preparation for it. Business and mercantile work are to-day interwoven with industrial work. Industrial work depends largely upon mechanical devices. The subject of mechanics should be given much emphasis as preparation of the boys for their chosen lifework. As comparatively few of the boys go to college it is essential that they get a good foundation in the principles and practical applications common in the business world, while they are in school.

It is not natural that a girl should have a very great interest in the details of mechanics; she does not expect to use special knowledge of machines much in the future and she is not in touch with mechanical devices at the time of studying physics. It is true that a teacher can work up interest in these topics among certain girls, but with the average girl this would be unnatural stimulation and not desirable.

I believe thoroughly in teaching some mechanics to girls. But I do not think it wise to go as deep into mechanics with girls as I would with a class of boys. Not that it would be too difficult, nor because of mathematics, but because it takes time to extend the subject, and there is a much richer field of study for girls in the subject of heat. There is much, also, in sound, light and electricity which should be included in a course for girls.

There must be life and human interest in a course in physics for girls. It must be awake to progress in the direction of their special interest. For example in considering the question of gas supply used in the home, show how it has developed that the purpose for which gas is used has changed. Formerly gas was used for its illuminating power almost wholly; now, since the 
advent of the gas range, people buy more gas for heating purposes than for illumination. Much of the lighting done is also due to the heating effect of the gas, as is the case where mantles are used.

The important thing to know about gas to-day is how much heat it will give rather than how much light. The question of establishing a heat standard in New York is at present before the authorities. Now is the time to bring this question before the physics class; especially is this interesting to a class of girls. They may follow the progress made and see how a standard for determining the quality of gas is obtained. They may consider whether the heat standard would have an advantage over the present photometric standard, both from the point of view of the consumer and of the producer.

One object which I have in mind when teaching physics is to put the pupil into such close touch with his environment that he will see in the commonplace things more than so much dead matter; I would vitalize matter; make an object commonly seen tell the observer some story. Let me illustrate by reference to the way I try to make thermometer mean more than "something" which tells temperature." In a demonstration lecture on the subject "temperature," the idea is emphasized by suitable illustrations that temperature and amount of heat are two different things. Question the value of knowing temperatures. Pupils will suggest many cases where it is important to know temperatures. Discuss temperature of human body, variations in this; temperature and health; cold and warm blooded animals. Extremes of temperature on surface of the earth; increase in interior and decrease as ascend above the earth. Temperature of moon, sun, space. Extremes of temperature reached artificially, for what purposes. Possible ways of measuring temperatures; historical development of temperature measuring instruments. The common thermometers. Method of making a mercury thermometer. One double period is given to the pupils to start making a mercury thermometer. In previous work they have had some experience in blowing bulbs in glass tubing. With the thermometer tubing, it is more difficult and I do not expect many thermometers will be made. With good luck a girl will get a bulb blown, filled with mercury and perhaps the tube sealed. Possibly one may even get the boiling and freezing points marked. Four-fifths of the class will not get the tube filled and sealed. I tell them if they wish they may finish it by putting in extra 
time. Some of them will not be interested enough to do extra work upon it while others will ask if they may come after school to finish it. But whether they finish it or not they will have a different mental attitude toward thermometers. They know the industrial history of the thermometer. In my class this year a girl made a thermometer, marked the scale and mounted it in two hours' time. I showed the completed thermometer to the class of boys who are preparing for college. Thermometer making is not in their course. On their own initiative I had onethird of the boys in the laboratory that afternoon after school trying to make a thermometer. The interest created in this way is natural and wholesome and I believe there is just as valuable laboratory practice in it for high school pupils as there is in "Finding the Error in the Fixed Points of a Mercury Thermometer" or the "Coefficient of Cubical Expansion of a Gas at Constant Pressure."

I wish to suggest a number of experiments in heat which I am using with a class of girls:

I. Conductivity of materials: Sand, air, iron, cotton, straw, paper, asbestos and sawdust are tested.

2. Absorption and Radiation of Heat: (a) Absorption; two thermometer, the bulb of one painted dull black, are placed at same distance from some heat supply. (b) Radiation; two calorimeters, one painted a dull black, the other bright and polished, are filled with hot water; note fall in temperature at regular intervals.

3. Convection: (a) in liquids; (b) in gases.

4. Ventilation: Test air currents in room. Test purity of air by the carbon dioxide determination.

5. Combustion of Fuels: Wood, coal, oil, alcohols. Test products, carbon dioxide, water and carbon monoxide when combustion is incomplete owing to a limited air supply.

6. The Bunsen Burner.

7. A Study of the Gas Stove (Bunsen Type). (a) As a cooker; (b) as a heater; (c) as combined heater and cooker.

8. A Study of the Kerosene Stove (a) as a cooker; (b) as a heater.

9. A Study of the Alcohol Stove (a) as a cooker; (b) as a heater.

Compare the results of 7,8 and 9 considering efficiency, cost and the changes they effect upon the air of the room. 
Io. A Study of the Electric Stove. (Work with this stovg is postponed until the subject of electricity is undertaken.)

Ir. Testing the Accuracy of the Gas Meter. Practice in Meter Reading.

i2. Cost of Cooking Various Dishes on the Gas Range. Relative cost when cooking large or small amounts.

I3. Testing an Alcohol-heated Flatiron.

I4. Comparative Tests with Denatured Alcohol, Wood Alcohol and Ethyl Alcohol as Fuel for the Chafing Dish.

I5. Making a Fireless Cooker and Testing its Efficiency; (a) as a Cooker; (b) as a Refrigerator or Cold Box. In selecting non-conducting material, make use of information found in exp. I on Conductivity.

I6. Cooling through Change of State.

I7. Heat of Fusion of Ice.

18. To Determine the Melting Point of: (a) Paraffin; (b) Butter; (c) Lard; (d) Olive Oil.

19. Freezing Mixtures.

20. Tests Made on a Refrigerator, Temperature, Ice Constumption and Heat Absorbed.

2I. Effect of Evaporation upon Temperature.

22. Temperature Change Resulting from Expansion and Compression of a Gas. Production of a Fog by Sudden Expansion of Moist Air.

23. Dew Point and Relative Humidity.

24. Pasteurization of Milk; Test Acidity of Milk: (a) when fresh.

(b) Unpasteurized and kept at room temperature for two days.

(c) Unpasteurized and kept in the refrigerator for two days.

(d) Pasteurized and kept at room temperature for two days.

(e) Pasteurized and kept in refrigerator for two days.

25. Flash Point and Burning Point (Fire Test) of kerosene, lard and alcohol.

26. Relation of Boiling Point to Pressure: (a) increasing pressure; (b) decrease iri pressure.

27. The Boiling Point of Alcohol.

28. Fractionai Distillation: Separate Alcohol from Water.

29. The Use of Volatile Inflammable Liquids.

Much of the work in this girls' course is related to domestic science. Where domestic science is taught in the school, each department should supplement the work of the other. 